\title{
IMPROVEMENT OF POWER QUALITY IN WIND ENERGY APPLICATIONS USING A DSTATCOM COUPLED WITH A FLYWHEEL ENERGY STORAGE SYSTEM
}

\author{
Gastón O. Suvire, Pedro E. Mercado \\ CONICET (Consejo Nacional de Investigaciones Científicas y Técnicas) and Instituto de Energía Eléctrica - UNSJ \\ San Juan, Argentina \\ e-mails: gsuvire@iee.unsj.edu.ar,pmercado@iee.unsj.edu.ar
}

\begin{abstract}
The inclusion of wind power in power systems is steadily increasing around the world. This incorporation can generate a number of problems on the dynamics of power systems. In addition, over the last few years, new power electronic devices coupled with energy storage have emerged. These new devices allow the operation of electric systems to be controlled. In this work, the use of a Distribution Static Synchronous Compensator (DSTATCOM) coupled with a Flywheel Energy Storage System (FESS) is proposed to mitigate problems, mainly in power quality, introduced by wind generation in the electric system. A dynamic model of the DSTATCOM/FESS device is presented and a multi-level control technique is proposed. The control technique has one control mode for active power and two control modes for reactive power, power factor correction, and voltage control. Tests of the behaviour of the device are analyzed when it is combined with wind generation in the electric system. The results demonstrate a satisfactory performance of the control technique proposed as well as a high effectiveness of the device, to mitigate problems introduced by wind generation.
\end{abstract}

Keywords - DSTATCOM, Flywheel Energy Storage, Wind Power.

\section{INTRODUCTION}

Wind power generation is considered the most economic viable alternative within the portfolio of renewable energy resources. Among its main advantages there are the large number of potential sites for plant installation and a rapidly evolving technology, with many suppliers offering from individual turbine sets to turnkey projects. However, the lack of controllability over the wind and the type of generation system used, provoke that wind generation causes problems to the electric systems. Among such problems there are those produced by wind power short-term fluctuations, e.g., in the power quality and in the dynamics of the system [1-3]. In addition, the reduced cost of power electronic devices as well as the breakthrough of new technologies in the field of electric energy storage makes it possible to incorporate this kind of storage with electronic control into the power systems [4]. These devices allow to control dynamically both voltage and flows of active and reactive power. Therefore, they offer a great potential in their use to mitigate problems introduced by wind generation.

Manuscript received on 29/10/2009. Revised on 22/04/2010 and 28/06/2010. Accepted for publication in $29 / 06 / 2010$ by recommendation of the Editor Fernando L. M. Antunes.
Based on the results obtained by analyzing different selection criteria, a Distribution Static Synchronous Compensator (DSTATCOM) coupled with a Flywheel Energy Storage System (FESS) has been proposed as the most appropriate system to contribute to the smooth of wind power short-term fluctuations [5]. A DSTATCOM is a fastresponse, solid-state power controller which provides flexible voltage control at the point of connection to the utility distribution feeder for power quality improvements [6]. This device can exchange both active and reactive power if an energy storage system is included into the DC bus. A FESS stores kinetic energy in a rotating mass and it has been used as short-term energy storage device. It can provide fast speed of response, excellent cycling characteristics and high electric efficiencies [7]. All these characteristics enable the DSTATCOM/FESS to mitigate voltage fluctuations and correct the power fluctuations of a wind power system. With these aspects in mind, it is necessary to consider carefully the information obtained from models that simulate the dynamic interaction between the DSTATCOM/FESS device and power systems with wind generation. Such models allow performing the necessary preliminary studies before connecting the DSTATCOM/FESS to the grid.

The aim of this paper is to discuss the dynamic performance of a DSTATCOM controller coupled with FESS to improve the integration of wind generators (WGs) into a power system. A WG-DSTATCOM/FESS system is proposed to minimize problems introduced by wind generation and to improve the power quality in the connexion point. Modelling and multi-level control approaches are proposed, including three modes of operation of the DSTATCOM/FESS device, namely, voltage control, power factor correction, and active power control. Validation of both models and control schemes is carried out through simulations by using SimPowerSystems of SIMULINK/ MATLAB ${ }^{\mathrm{TM}}$.

\section{MODELLING OF THE DSTATCOM/FESS}

In order to study the dynamic performance of the DSTATCOM/FESS controller, a model of the combined system is proposed (see Figure 1). This model consists mainly of the DSTATCOM controller, the Interface converter and the FESS device. The basic component of the DSTATCOM is the voltage-source inverter (VSI) with semiconductors devices having turn-off capabilities [6]. Other components are the coupling step-up transformer, the line connection filter and the DC bus capacitor. The Interface converter couples the DC bus of the DSTATCOM with the FESS device, which the basic component is a VSI. The FESS 
device is mainly made up of a motor/generator and a flywheel.

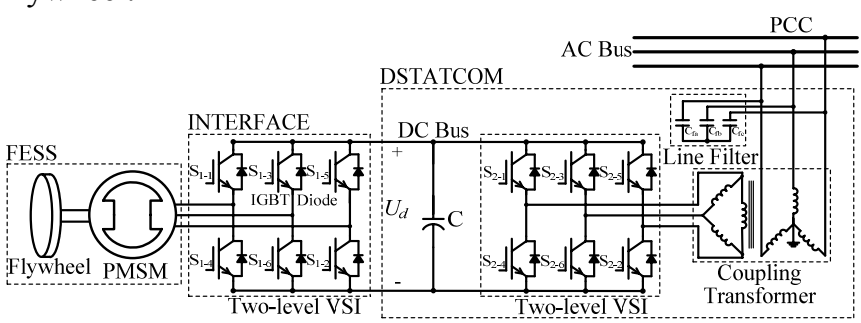

Fig. 1. Representation of the DSTATCOM/FESS controller

The DSTATCOM and the Interface converter use twolevel VSIs. The used commutation valves are Insulated Gate Bipolar Transistors (IGBT) with anti-parallel diodes. The VSIs are modelled with detailed blocks of the switches and diodes incorporated into the simulation program. The technique of sinusoidal pulse width modulation (SPWM) is used to obtain a sinusoidal voltage waveform. The SPWM of the VSI in the Interface converter works with a frequency higher than that of the DSTATCOM. The interface VSI needs a voltage with a higher frequency to operate the FESS machine at high speeds. In order to reduce the disturbance produced on the distribution system by the high-frequency switching harmonics generated by the SPWM control, a low pass sine wave filter is used. This filter is built with the leakage inductances of the step-up coupling transformer windings and a bank of capacitors.

FESSs extract the electric energy from a primary source, such as an electric grid, and store it as kinetic energy in its rotating mass. The energy stored by a flywheel is calculated by using (1).

$$
\Delta E=\frac{1}{2} J\left(\omega_{\max }^{2}-\omega_{\min }^{2}\right)
$$

where $\Delta E$ is the energy stored by the flywheel, $\omega_{\max }$ and $\omega_{\min }$ are, respectively, the maximum and minimum operation speed of the flywheel, and $J$ is the moment of inertia of the flywheel.

The power between the flywheel and the Interface converter is exchanged by using a Permanent Magnet Synchronous Machine (PMSM). This machine allows the operation at high speeds due to the fact that the type of rotor used is brushless and without winding. The PMSM is modelled with a detailed block included in the simulation program and with parameters obtained from the manufacturer data sheets [7-9]. The flywheel is modelled as an additional mass coupled to the rotor shaft of the PMSM [10].

\section{DSTATCOM/FESS CONTROL}

The control proposed for the DSTATCOM/FESS device is divided into two parts, the DSTATCOM control and the FESS control. For each part, a multi-level control scheme is suggested. This scheme has its own control objectives for each level. In this way, a system of complex control is divided into several control levels, which are simpler to design $[11,12]$. Both parts of the multi-level control scheme, i.e., the DSTATCOM and the FESS, are divided into three quite distinct levels: external, middle and internal level, shown in simplified way in Figure 2.

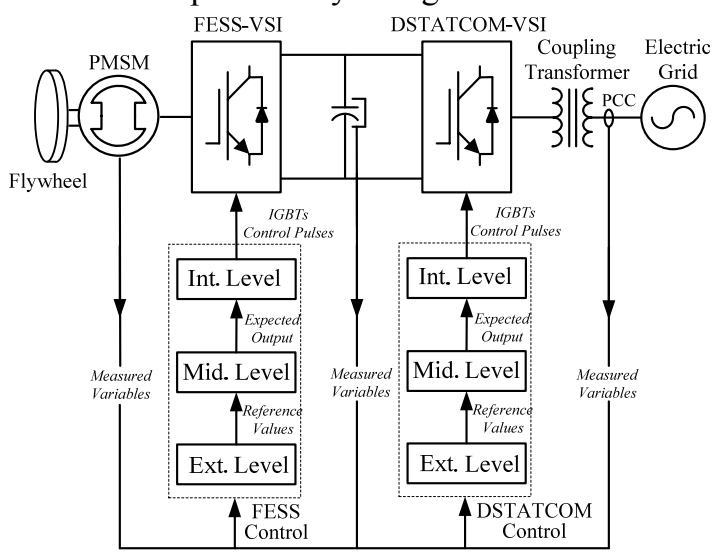

Fig. 2. Structure of the multi-level control of the DSTATCOM/ FESS

\section{A. DSTATCOM Control}

Each control level of the DSTATCOM has certain functions. The external level is responsible for determining the active and reactive power exchange between the DSTATCOM and the utility system. The middle level control allows the expected output to dynamically track the reference values set by the external level. The internal level is responsible for generating the switching signals for the valves of the VSI of the DSTATCOM. The control algorithm of the DSTATCOM with all its parts in detail is shown in Figure 3 .

Control is performed with the synchronous-rotating dq reference frame. The coordinate system is defined with the daxis always coincident with the instantaneous voltage vector $\left(u_{d}=|u|, u_{q}=0\right)$. Consequently, the d-axis current component contributes to the instantaneous active power and the q-axis current component represents the instantaneous reactive power.

\section{1) External Level Control}

The proposed external level control scheme (left side in Figure 3) is designed for performing three major control objectives, namely the voltage control mode (VCM), which is activated when switch $S$ is in position $a$, the power factor control mode (PFCM), activated in position $b$, and the active power control mode (APCM), which is always activated. The active power control mode can be used because the DSTATCOM is coupled with the storage device.

The VCM consists in controlling the voltage at the PCC (Point of Common Coupling) of the DSTATCOM through the modulation of the reactive component of the output current. To this aim, the instantaneous voltage at the PCC $\left(u_{d}\right)$ is computed by using a synchronous-rotating orthogonal reference frame and is then compared with a reference voltage $\left(U_{r}\right)$. A voltage regulation droop $R_{q}$ is included in order to allow the terminal voltage of the DSTATCOM/FESS to vary in proportion to the compensating reactive current. As a result, the PI controller with droop characteristics becomes a simple phase-lag compensator. 


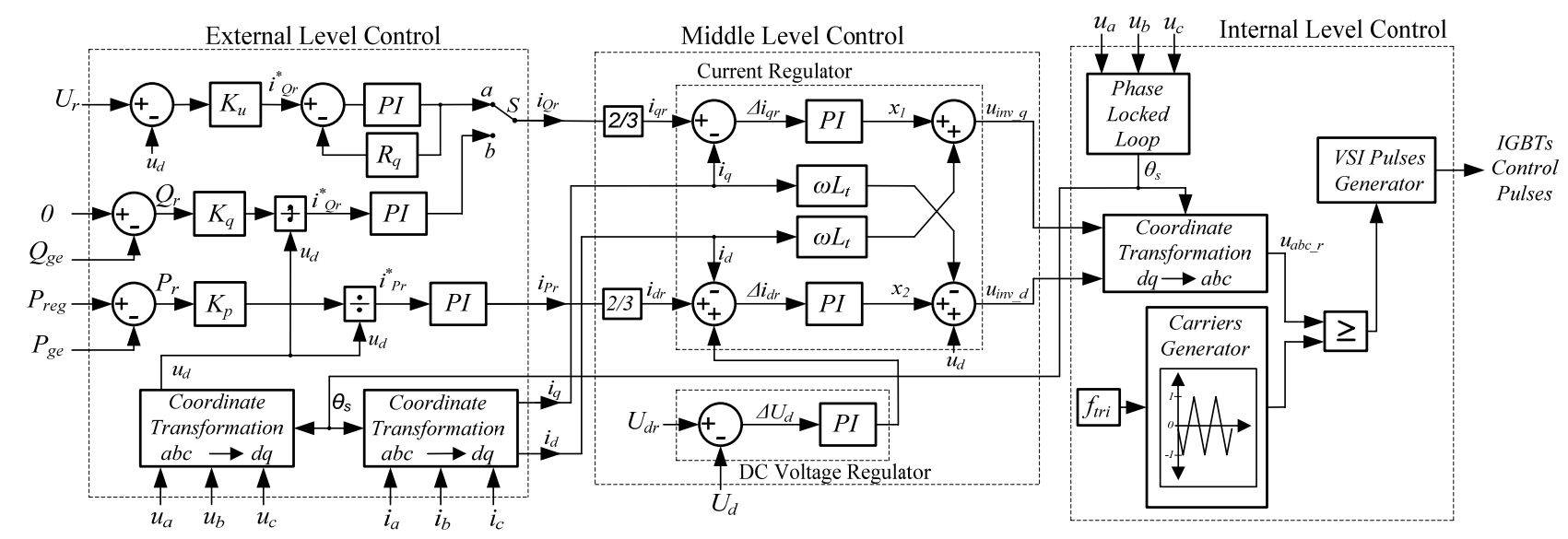

Fig. 3. Multi-level control scheme of the DSTATCOM device.

In the PFCM, the reactive power reference $\left(Q_{r}\right)$ is set to the measured value of the reactive power of wind generation $\left(Q_{g e}\right)$. In this way, all the reactive power required by the WG is provided and thus the WG-DSTATCOM/FESS system is able to maintain the unitary power factor. A standard PI compensator is included to eliminate the steady-state error in the reactive current reference computation.

The APCM allows controlling the active power exchanged with the electric system. The computation of the reference active power $\left(P_{r}\right)$ depends on the active power value injected by the wind generation. This value is the difference between the desirable regulation power $\left(P_{\text {reg }}\right)$ and the measured active power from the WG $\left(P_{g e}\right)$. The $P_{\text {reg }}$ is the active power that needs to be delivered to the electric system by the WG DSTATCOM/FESS system. A standard PI compensator is also included to eliminate the steady-state error in the active current reference computation.

\section{2) Middle Level Control}

This block has two main parts, the DC voltage regulator and the current regulator. A functional simplified scheme of this control level is shown in the central part of Figure 3.

The dynamic equations governing the power instantaneous transfer between the DSTATCOM and the electrical network are given by $(2)[13,14]$.

$$
\frac{d}{d t}\left[\begin{array}{l}
i_{q} \\
i_{d}
\end{array}\right]=\left[\begin{array}{cc}
-\omega & -R_{t} / L_{t} \\
-R_{t} / L_{t} & \omega
\end{array}\right]\left[\begin{array}{l}
i_{d} \\
i_{q}
\end{array}\right]+\frac{1}{L_{t}}\left[\begin{array}{c}
u_{i n v-q} \\
u_{i n v-d}-|u|
\end{array}\right]
$$

where $R_{t}$ and $L_{t}$ are, respectively, the resistance and equivalent leakage inductance of the coupling transformer of the DSTATCOM.

A control methodology to obtain a decoupled control of the current components, $i_{d}$ and $i_{q}$, is derived from (2). To achieve this objective, the first term of (2) is cancelled and the voltage variables are cleared out.

$$
\begin{aligned}
& u_{i n v-q}=L_{t}\left(i_{q} R_{t} / L_{t}+\omega i_{d}\right) \\
& u_{i n v-d}=L_{t}\left(i_{d} R_{t} / L_{t}-\omega i_{q}\right)+|u|
\end{aligned}
$$

To control the output voltage of the VSI, the instantaneous currents and their derivatives have to be decoupled. This can be accomplished by generating two appropriate control signals $x_{1}$ and $x_{2}$. If $i_{q} R_{t} / L_{t}=x_{1}$ and $i_{d} R_{t} / L_{t}=x_{2}$, and these variables are introduced in (3); then, replacing (3) in (2) it results in (4).

$$
\frac{d}{d t}\left[\begin{array}{l}
i_{q} \\
i_{d}
\end{array}\right]=\left[\begin{array}{cc}
0 & -R_{t} / L_{t} \\
-R_{t} / L_{t} & 0
\end{array}\right]\left[\begin{array}{l}
i_{d} \\
i_{q}
\end{array}\right]+\left[\begin{array}{l}
x_{1} \\
x_{2}
\end{array}\right]
$$

As can be noticed from the equation above, $i_{d}$ and $i_{q}$ respectively respond to $x_{1}$ and $x_{2}$ with no cross-coupling. In this way, the introduction of these new control variables allows to obtain a full model reduced to two first-order functions, which considerably improves the control system performance. Conventional PI controllers with proper feedback from the DSTATCOM/FESS output current component are used to obtain the decoupling condition.

In addition, the AC and DC sides of the DSTATCOM are related to the power balance between the input and the output as described by (5).

$$
P_{A C}=\frac{3}{2}\left(u_{i n v_{-} d} i_{d}+u_{i n v_{-} q} i_{q}\right)=-C U_{d} \frac{d U_{d}}{d t}-\frac{U_{d}^{2}}{R_{p d}}=P_{D C}
$$

where $R_{p d}$ is the loss resistance of the VSI and $U_{d}$ is the DC voltage. Considering $u_{i n v \_d}=k_{i n v} \cos \alpha U_{d}$ and $u_{i n v_{q} q}=k_{\text {inv }} \sin \alpha U_{d}$, with $k_{\text {inv }}=m_{a} a_{t} / 2,\left(m_{a}\right.$ modulation index, $a_{t}=n_{1} / n_{2}$ : voltage ratio of the coupling transformer) and $\alpha$ is the phase-shift between the converter output voltage and the grid AC voltage; (5) may be rewritten as:

$$
\frac{d U_{d}}{d t}=-\frac{3}{2} \frac{1}{C} k_{i n v} \cos \alpha i_{d}-\frac{3}{2} \frac{1}{C} k_{i n v} \sin \alpha i_{q}-\frac{U_{d}}{C R_{p d}}
$$

Another PI compensator for eliminating the steady-state voltage variations at the DC bus is used by forcing a small active power exchange with the electric grid.

\section{3) Internal Level Control}

A basic scheme of the internal level control of the DSTATCOM is shown on the right side of Figure 3. This level is mainly composed of a line synchronization module and a three-phase PWM firing pulses generator for the DSTATCOM VSI. The line synchronization module consists mainly of a phase locked loop (PLL). This module recovers and synthesizes the information of the frequency and phase of the positive sequence components of the AC voltage of the electric system [14]. The three-phase firing pulses generator produces both a frequency triangular wave $\left(f_{t r i}\right)$ and the firing 
pulses for each IGBT of the VSI by comparing this triangular wave with the desired reference three-phase voltage, $u_{a b c_{-} r}$.

\section{B. FESS Control}

The FESS control is carried out through the control of the Interface-VSI. By establishing a three-phase voltage of controllable amplitude and phase with the VSI, the PMSM can work as a motor storing energy or as generator delivering energy. In a similar way to the DSTATCOM control, each control level has to perform certain functions. The external level is responsible for determining the power exchange between the DC bus of the DSTATCOM and the FESS, so as to fulfil the power requirements imposed by the DSTATCOM. The middle and internal levels basically have the same functions as the middle and internal control levels of the DSTATCOM respectively. The control algorithm of the FESS is shown in Figure 4.

\section{1) External Level Control}

The external level control of the FESS is shown in simplified way on the left side of Figure 4. In this control scheme, the reference current $i_{q m r}$ is computed from the torque of the PMSM by using (7), and the reference current $i_{d m r}$ is set to zero. In this way, a maximum efficiency of the PMSM is obtained [15].

$$
T_{e_{-} r}=\frac{3}{2} p \psi_{m} i_{q m r}
$$

where $T_{e_{r} r}$ is the electromagnetic torque of the machine, $p$ the number of pairs of poles and $\psi_{m}$ the magnetic flux.

The reference torque is calculated through a speed regulator which adjusts the actual speed of the machine $\left(\omega_{m}\right)$ to the reference speed of the machine $\left(\omega_{m r}\right)$ by using a PI controller. The reference speed is computed from the reference power of the machine, $P_{\text {mac_r }}$, (the power to be stored or delivered by the flywheel) using (8).

$$
P_{m a c_{-} r}=\frac{d\left(1 / 2 J \omega_{m r}^{2}\right)}{d t}
$$

The reference power of the machine is calculated by summing up the reference power of the DSTATCOM/FESS $\left(P_{r}\right)$ and the power losses of the machine $\left(P_{\text {loss }}\right)$. The losses of the machine are computed by summing up the copper losses $\left(P_{C u}\right)$, the iron losses $\left(P_{F e}\right)$ and the mechanical losses $\left(P_{m e c}\right)$.

The copper losses depend on the current injected or consumed by the machine and they are calculated by using (9).

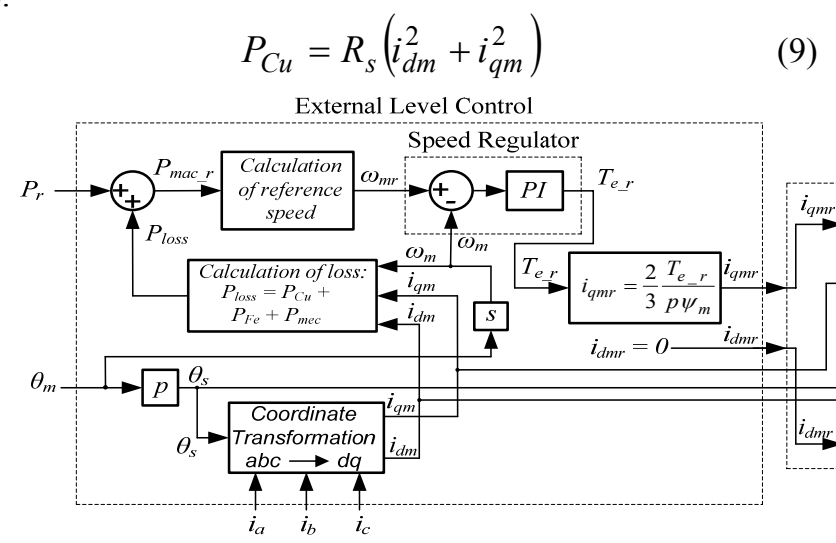

Core losses (or iron losses) are due to both eddy currents and magnetic hysteresis in the iron laminations. These losses are computed by using (10) [16].

$$
\begin{gathered}
P_{F e}=\rho_{F e} V \\
\rho_{F e}=\rho_{h y s t}+\rho_{e d d y}=k_{h y s t} B_{m}^{\beta_{s t}} \omega+k_{e d d y} B_{m}^{2} \omega^{2}
\end{gathered}
$$

where $V$ is the estimated volume of the stator, $\rho_{F e}$ is the total loss-density in the iron, $\rho_{\text {hyst }}$ and $\rho_{\text {eddy }}$ are the hysteresis and the eddy current loss-density respectively, $B_{m}$ is the magnetic flux density, $\omega$ the angular frequency, $k_{h y s t}$ and $k_{\text {eddy }}$ are, respectively, the hysteresis and eddy current constants and $\beta_{S t}$ is the Steinmetz constant.

Finally, the mechanical losses, mainly due to friction, are computed by using (12).

$$
P_{m e c}=F_{m} \omega_{m}^{2}
$$

where $F_{m}$ is the friction coefficient and $\omega_{m}$ is the mechanical angular speed of the machine.

\section{2) Middle Level Control}

A functional simplified scheme of middle level control is shown in the central part of Figure 4. This level is basically composed of a current regulator. The control is made by using vector control; the main characteristic of this control is the synchronization of the stator flux with the rotor. The currents in the $\mathrm{d}$ and $\mathrm{q}$ axes are regulated separately. The control scheme is similar to the middle level control of the DSTATCOM, except that the synchronism angle to make the coordinate transformation, $\theta_{s}$, is computed in a different way. In this case, the angle is obtained by measuring the position angle of the machine $\left(\theta_{m}\right)$ and multiplying it by the number of pairs of poles.

\section{3) Internal Level Control}

A basic scheme of the internal level control of the FESS is shown on the right side of Figure 4. This control level is quite similar to that of the internal level control of the DSTATCOM, except that it does not have the phase locked loop block due to the fact that the angle $\theta_{s}$ is obtained through measurement as mentioned before.

\section{TEST SYSTEM}

The test power system used to study the dynamic performance of the proposed DSTATCOM/FESS device is shown in Figure 5 as a single line diagram. This subtransmission system operates at $13.8 \mathrm{kV} / 50 \mathrm{~Hz}$ and implements a dynamically modelled wind generator linked to

Fig. 4. Multi-level control scheme of the FESS 
a bulk power system represented by an infinite bus type.

The WG uses an induction generator with a squirrel-cage rotor and is connected to the grid through a transformer with star-triangle winding. The demand for reactive power from the WG is supplied by capacitors so as to reach a close-toone power factor. The WG is modelled with blocks of an induction generator and a wind turbine available in the library of the simulation program and with parameters taken from the manufacturer data sheets $[17,18]$. The subtransmission line is modelled by using lumped parameters. All loads are modelled by constant impedances and are grouped at bus 4 .

The DSTATCOM/FESS device proposed is connected to the main bus (bus 3). The DC voltage of the DSTATCOM is $750 \mathrm{~V}$ and the capacitor used is $1000 \mu \mathrm{F}$. The DSTATCOMVSI works with a frequency of $8 \mathrm{kHz}$ whereas the InterfaceVSI works with $20 \mathrm{kHz}$. The parameters of the FESS (PMSM and flywheel) are obtained from the manufacturer data sheets [7-9].

The major test system data are summarized in Appendix A while the DSTATCOM/FESS data are in Appendix B. The constants data of the control algorithm of the DSTATCOM/FESS device are included in Appendix C.

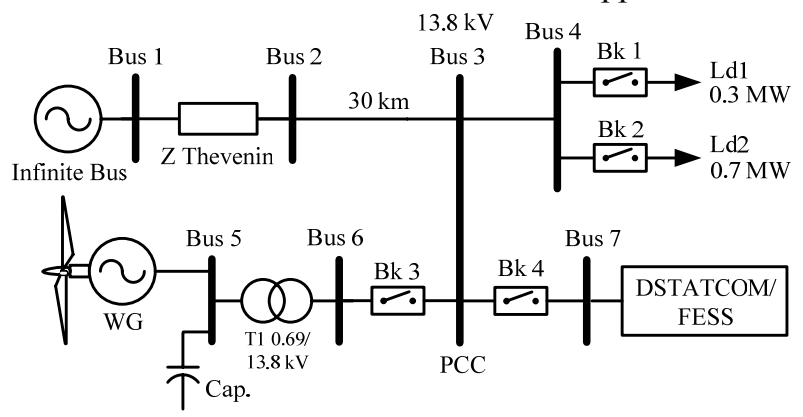

Fig. 5. Test power system

The analysis and validation of the proposed models and control algorithms for the DSTATCOM/FESS controller are carried out through simple events that impose high demands upon the dynamic response of the device. For this, a variation profile of wind speed is applied to the WG so that the DSTATCOM/FESS works in both ways, by storing and delivering energy. In addition, external perturbations such as load variations are imposed and the behaviour of the device in the different control modes is observed.

\section{SIMULATION RESULTS}

The basic system shown in Figure 5 is used. A suitable profile for variation of the wind speed is applied, as shown in Figure 6.

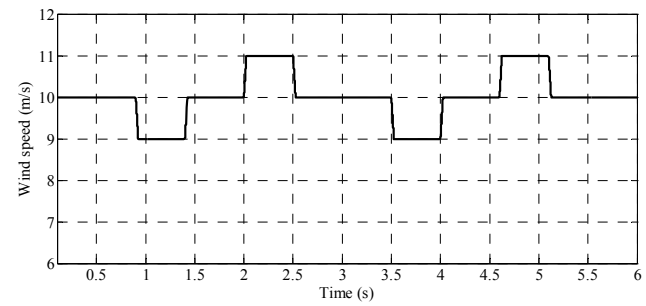

Fig. 6. Wind speed

The wind speed variations cause significant fluctuations in the active and reactive power injected by the WG. The used capacitor bank with the WG is adjusted to compensate the reactive power when the WG operates at a mean wind speed of $10 \mathrm{~m} / \mathrm{s}$. In bus 4 , the load Ld1 $=0.3 \mathrm{MW}$ is first connected (in $\mathrm{t}=0 \mathrm{~s}$ ) and then, in $\mathrm{t}=3 \mathrm{~s}$, the load $\mathrm{Ld} 2=0.7 \mathrm{MW}$ is added. The behaviour of the system is analyzed when the DSTATCOM/FESS is disconnected (Bk4 opened) and connected (Bk 4 closed). The variations of active power injected by the WG-DSTATCOM/FESS system for both cases are shown in Figure 7. With the DSTATCOM/FESS device connected, the variations of power from the WG are reduced and an active power that is practically constant is injected to the system.

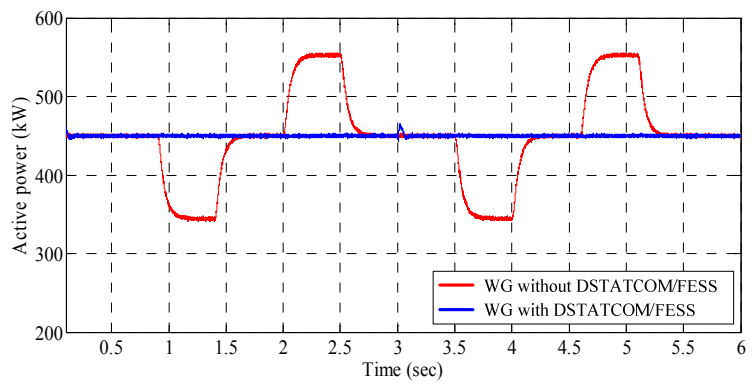

Fig. 7. Active power of the WG-DSTATCOM/FESS system

For the reactive power control, three different cases are presented: DSTATCOM/FESS disconnected, DSTATCOM/ FESS connected working in Power Factor Control Mode (PFCM); and DSTATCOM/FESS connected working in Voltage Control Mode (VCM).

The reactive power injected by the WG-DSTATCOM/ FESS system is shown in Figure 8 . With the DSTATCOM/FESS connected working in PFCM, it is observed that the reactive power injected by the WGDSTATCOM/FESS system is zero. Consequently, the proposed device has satisfactorily compensated the reactive power variations of the WG. With the DSTATCOM/FESS connected working in VCM, the reactive power variations from the WG are compensated and the device also generates or consumes the reactive power necessary to make the voltage in bus 4 be 1 pu.

The voltage at bus 4 is shown in Figure 9. When there is no compensation, the voltage has significant variations due to both the power variations from the WG and those of the load. When the DSTATCOM/FESS device is connected in PFCM, there are no voltage variations due to wind power variations. However, this mode presents the problem that the voltage has a value different from $1 \mathrm{pu}$ and it varies with disturbances in the load. When the DSTATCOM/FESS device is connected in VCM, the voltage is maintained at 1 $\mathrm{pu}$ independently of the variations in wind power and variations of the load. This control mode solves in quite effective way the problem observed with the PFCM. Therefore, the VCM is the most convenient mode when the connection point of the WG does not have any other device that dynamically controls the voltage.

The obtained results show that the DSTATCOM/FESS device compensates effectively the power fluctuations coming from a WG. Additionally, due to the fast speed of response of the device (3-5 $\mathrm{ms}$ [7-9]) it can be used to compensate deep voltage sags on the grid. Moreover, the DSTATCOM/FESS could provide the power system with 
other services such as: spinning reserve, Uninterruptible Power Supply (UPS), system stability, load following, etc.

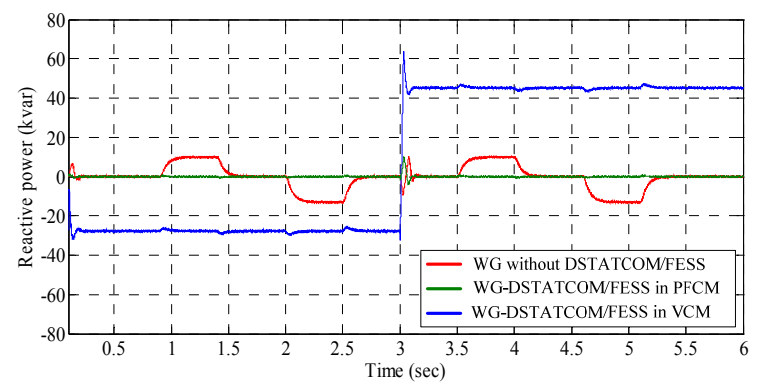

Fig. 8. Reactive power of the WG-DSTATCOM/FESS system

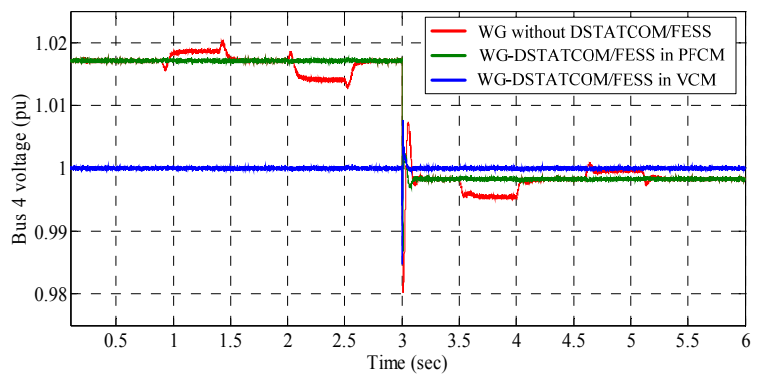

Fig. 9. Voltage at bus 4

\section{CONCLUSIONS}

This paper presents model aspects and control algorithms of a DSTATCOM controller coupled with a Flywheel Energy Storage System. A proposal is made of a detailed fully realistic model of the compensator and a novel multilevel control algorithm based on a decoupled current control strategy in the synchronous rotating d-q reference frame. The incorporation of the DSTATCOM/FESS in the electric system with wind generation was studied, and its behaviour analyzed in different control modes.

From the results obtained, it can be concluded that with the proposed device and control mode, the power fluctuations coming from a WG are effectively compensated. It was shown that the WG-DSTATCOM/FESS system can deliver a constant active power in a time range of seconds or more, depending on the storage capacity. For the reactive power control, it was shown that the proposed system is able to provide a unitary power factor or to obtain a dynamic control of the voltage in the connection point. The voltage control operates satisfactorily in case of power disturbances in the WG and also for fluctuations in the system such as sudden variations in the load. Therefore, the incorporation of DSTATCOM/FESS has shown that it can improve the power quality in wind power systems.

\section{REFERENCES}

[1] T. Ackermann, Wind Power in Power systems, John Wiley\&Sons, Ltd, ISBN 0-470-85508-8 (HB), 2005.

[2] G. O. Suvire and P. E. Mercado, "Impacts and Alternatives to Increase the Penetration of Wind Power Generation in Power Systems", $X$ Symposium of
Specialists in Electric Operational and Expansion Planning (SEPOPE), Florianopolis - Brazil, may 2006.

[3] G. O. Suvire and P. E. Mercado, "Wind Farm: Dynamic Model and Impact on a Weak Power System", IEEE PES T\&D LATINAMERICA, Bogotá-Colombia, August 2008.

[4] R. Brad and J. McDowall, "Commercial Successes in Power Storage", IEEE power \& energy magazine, march/april 2005

[5] G. O. Suvire and P. E. Mercado, "Utilización de Almacenadores de Energía para Mitigar los Problemas Introducidos por la Generación Eólica en el Sistema Eléctrico", Décimo Segundo Encuentro Regional Iberoamericano del CIGRE, Foz do Iguazú-Pr, Brasil - mayo de 2007.

[6] Y. H. Song and A. T. Johns, Flexible AC Transmission Systems (FACTS), IEE Press, ISBN 0-85296-771-3, 1999.

[7] Beacon Power website, www.beaconpower.com/, March 2009.

[8] Flywheel Energy Systems website, www.magma.ca/ fesi, March 2009

[9] Urenco Power Technologies website, uptenergy.com, March 2009.

[10] S. Samineni, B. K. Johnson, H. L. Hess, J. D. Law, "Modeling and Analysis of a Flywheel Energy Storage System for Voltage Sag Correction", IEEE Transactions on Industry Applications, Vol.. 42, No. 1, Janaury/February 2006.

[11]H. Xie, S. Mei and Q. Lu, "Design of a Multi-Level Controller for FACTS Devices", Proc. Power Systems and Communication Infrastructures for the Future, Pekín, China, September 2002.

[12] M. G. Molina and P. E. Mercado, "Multilevel control of a Static Synchronous Compensator combined with a SMES coil for applications on Primary Frequency Control", Proc. CBA 2004, Gramado, Brazil, September 2004.

[13] M. H. Rashid, Power Electronic Handbook - Second Edition, Elsevier, ISBN 978-0-12-088479-7, 2007.

[14]B. K. Bose, Modern Power Electronics and AC Drives, Prentice Hall, ISBN 0-13-016743-6, 2002.

[15]H. Toliyat, S. Talebi, P. McMullen, C. Huynh and A. Filatov, "Advanced High-Speed Flywheel Energy Storage Systems for Pulsed Power Applications", IEEE Electric Ship Technologies Symposium, 2005.

[16] S. Meier, "Theoretical design of surface-mounted permanent magnet motors with fieldweakening capability", Master Thesis, Royal Institute of Technology - Department of Electrical Engineering Electrical Machines and Power Electronics, Stockholm 2001/2002.

[17] Neg Micon website, www.neg-micon.com, January 2009 [18] Ecotècnia website, www.ecotecnia.com, January 2009.

\section{APPENDIX A. TEST SYSTEM DATA}

Line data are given in Table I. Table II shows the transformer data. All p.u. quantities are on $13.8 \mathrm{kV}$ and the transformer rated MVA base. Table III shows the main parameters of the generation unit coupled to the wind turbine. Table IV shows the main parameters of the wind 
turbine and the power curve of the turbine is shown in Figure 10. All p.u. quantities are on a $690 \mathrm{~V}$ and on the $750 \mathrm{kVA}$ base. Finally, the most important load data are shown in Table V.

\section{TABLE I}

Line data

\begin{tabular}{cccccccc}
\hline ID & $\begin{array}{c}\text { From } \\
\text { bus }\end{array}$ & $\begin{array}{c}\text { To } \\
\text { bus }\end{array}$ & $\begin{array}{c}\boldsymbol{U}_{N} \\
\mathbf{k V}\end{array}$ & $\begin{array}{c}\boldsymbol{L} \\
\mathbf{k m}\end{array}$ & $\begin{array}{c}\boldsymbol{R} \\
\mathbf{\Omega} / \mathbf{k m}\end{array}$ & $\begin{array}{c}\boldsymbol{X} \\
\mathbf{\Omega} / \mathbf{k m}\end{array}$ & $\begin{array}{c}\boldsymbol{B} \\
\boldsymbol{\mu} \boldsymbol{\Omega}^{-\mathbf{1}} \mathbf{k m}\end{array}$ \\
\hline $\mathrm{L} 1$ & 2 & 3 & 13.8 & 30 & 0.01273 & 0.2933 & 4.0024 \\
\hline
\end{tabular}

ID: component identifier; $U_{N}$ : rated voltage; $L$ : line length; $R, X$ and $B$ : positive sequence resistance, reactance and susceptance of sub-transmission line.

TABLE II

Transformer data

\begin{tabular}{ccccccccc}
\hline ID & $\begin{array}{c}\text { From } \\
\text { bus }\end{array}$ & $\begin{array}{c}\text { To } \\
\text { bus }\end{array}$ & $\begin{array}{c}\boldsymbol{R} \\
\text { pu }\end{array}$ & $\begin{array}{c}X \\
\text { pu }\end{array}$ & $\begin{array}{c}\boldsymbol{R} \boldsymbol{m} \\
\mathbf{p u}\end{array}$ & $\begin{array}{c}\boldsymbol{X} \boldsymbol{m} \\
\mathbf{p u}\end{array}$ & $\begin{array}{c}\boldsymbol{S}_{N} \\
\mathbf{k V A}\end{array}$ & $\begin{array}{c}\boldsymbol{N}_{p} / \boldsymbol{N}_{\boldsymbol{s}} \\
\mathbf{k V} / \mathbf{k V}\end{array}$ \\
\hline $\mathrm{T} 1$ & 5 & 6 & 0.002 & 0.021 & 500 & 500 & 1000 & $0.69 / 13.8$ \\
\hline
\end{tabular}

$R$ and $X$ : winding resistance and reactance; $R_{m}$ and $X_{m}$ : magnetization resistance and reactance; $S_{N}$ : rated power; $N_{p} / N_{s}$ : voltage transformation ratio

TABLE III

Wind generator data

\begin{tabular}{llccccccc}
\hline \multirow{2}{*}{ ID Bus Machine } & \multirow{2}{*}{ Rotor } & $S_{N}$ & $U_{N}$ & $R s$ & $X s$ & $R r$ & $X r$ & $H$ \\
& & $k V A$ & $V$ & pu & pu & pu & pu & s
\end{tabular}

\begin{tabular}{lllllllllll}
\hline WG & 5 & Induction Squirrel-cage & 750 & 690 & 0.02 & 0.06 & 0.02 & 0.06 & 0.1 & 2
\end{tabular} $R_{s}$ and $X_{s}$ : stator resistance and reactance; $R_{r}$ and $X_{r}$ : rotor resistance and reactance; $H$ : inertia constant; $p$ : pairs of poles

TABLE IV

Wind turbine data

\begin{tabular}{ccccc}
\hline ID & $\begin{array}{c}\boldsymbol{H} \\
\mathbf{s}\end{array}$ & $\begin{array}{l}\boldsymbol{W} \boldsymbol{c - i} \\
\mathbf{m} / \mathbf{s}\end{array}$ & $\begin{array}{l}\boldsymbol{W c - o} \\
\mathbf{m} / \mathbf{s}\end{array}$ & $\begin{array}{l}\boldsymbol{W r p} \\
\mathbf{m} / \mathbf{s}\end{array}$ \\
\hline $\mathrm{WT}$ & 2 & 4 & 25 & 16 \\
\hline
\end{tabular}

$W_{c-i}$ : cut-in wind speed; $W_{c-o}$ : cut-out wind speed; $W_{r p}$ : rated wind speed

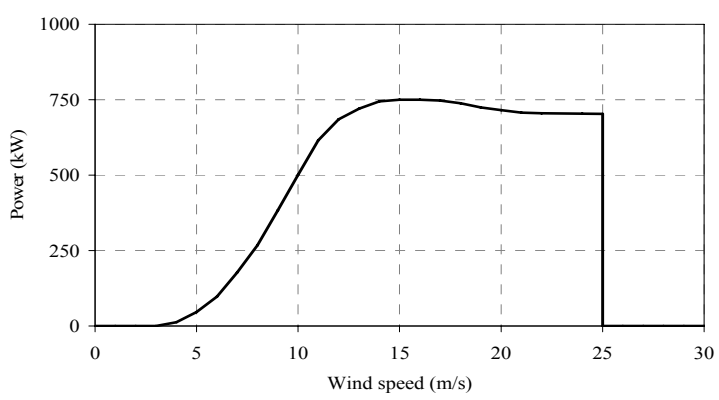

Fig. 10. Power curve of the wind turbine

TABLE V

Load data

\begin{tabular}{cccc}
\hline ID & Bus & $\begin{array}{l}\boldsymbol{P}_{\boldsymbol{L}} \\
\mathbf{k W}\end{array}$ & $\begin{array}{c}\boldsymbol{Q}_{\boldsymbol{L}} \\
\mathbf{k v a r}\end{array}$ \\
\hline Ld1 & 4 & 300 & 0 \\
\hline Ld2 & 4 & 700 & 0 \\
\hline
\end{tabular}

$P_{L}$ and $Q_{L}$ : load real and reactive power.

\section{APPENDIX B. DSTATCOM/FESS CONTROLLER DATA}

Tables VI-VIII summarize the most important data corresponding to the FESS, Interface converter and DSTATCOM subsystems.
TABLE VI:

FESS data

\begin{tabular}{|c|c|c|c|c|c|c|c|}
\hline \multicolumn{8}{|c|}{ General } \\
\hline ID & $\begin{array}{l}P_{\max } \\
\mathrm{kW}\end{array}$ & $\begin{array}{c}E \\
\text { Wh }\end{array}$ & $\begin{array}{r}t_{d} \\
\mathbf{s}\end{array}$ & $\begin{array}{c}S_{\min } \\
\text { krpm }\end{array}$ & $\begin{array}{c}S_{\max } \\
\text { krpm }\end{array}$ & $\begin{array}{c}J \\
\mathrm{~kg} \mathrm{~m}^{2}\end{array}$ & $\begin{array}{c}\boldsymbol{U}_{\boldsymbol{d}} \\
\mathbf{V}\end{array}$ \\
\hline FW & 100 & 750 & 27 & 15.5 & 31 & 0.72 & 750 \\
\hline
\end{tabular}

$P_{\max }:$ maximum rated real power; $E$ : rated storage capacity; $t_{d}$ : discharge time; $S_{\min }$ and $S_{\max }$ : minimum and maximum operation speed; $J$ : Polar inertia $\left(\mathrm{PMSM}+\right.$ flywheel); $U_{d}$ : DC voltage.

TABLE VII:

PMSM data

\begin{tabular}{clccc}
\hline \multicolumn{5}{c}{ PMSM } \\
\hline $\begin{array}{c}\text { Motor/ } \\
\text { Generator }\end{array}$ & $\begin{array}{c}\boldsymbol{\psi}_{\boldsymbol{m}} \\
\mathbf{W b}\end{array}$ & $\begin{array}{c}\boldsymbol{L}_{\boldsymbol{d}}, \boldsymbol{L}_{\boldsymbol{q}} \\
\boldsymbol{\mu H}\end{array}$ & $\begin{array}{c}\boldsymbol{R} \\
\mathbf{m} \boldsymbol{\Omega}\end{array}$ & $\boldsymbol{p}$ \\
\hline $\begin{array}{c}\text { Permanent Magnet } \\
\text { 3-phase, synchromous }\end{array}$ & 0.052 & 100 & 8 & 2 \\
\hline
\end{tabular}

$\psi_{m}$ : flux induced by magnet; $L_{d}$ and $L_{q}: \mathrm{d}$ and $\mathrm{q}$ axis inductances; $R$ : resistance of the stator windings.

TABLE VIII:

VSI data of the Interface converter and the DSTATCOM

\begin{tabular}{ccccc}
\hline $\boldsymbol{T}_{\boldsymbol{f}}$ & $\boldsymbol{T}_{\boldsymbol{t}}$ & $\boldsymbol{U}_{\boldsymbol{f}}$ & $\boldsymbol{R}_{\boldsymbol{o n}}$ & $\boldsymbol{R}_{\boldsymbol{s}}$ \\
$\boldsymbol{\mu} \mathbf{s}$ & $\boldsymbol{\mu s}$ & $\mathrm{V}$ & $\mathrm{m} \boldsymbol{\Omega}$ & $\mathbf{k} \boldsymbol{\Omega}$ \\
\hline 1 & 2 & 1 & 1 & 100 \\
\hline
\end{tabular}

$T_{f}$ : Current $10 \%$ fall time of the IGBT, $T_{t}$ : Current tail time of the IGBT; $U_{f}$ : forward voltage for IGBTs; $R_{o n}$ : internal resistance of the IGBT device; $R_{s}$ : snubber resistance

TABLE IX:

Transformer data of the DSTATCOM

\begin{tabular}{cccccccc}
\hline \multirow{2}{*}{ ID } & \multirow{2}{*}{ Bus } & $\begin{array}{c}\boldsymbol{R} \\
\mathbf{p u}\end{array}$ & $\begin{array}{c}\boldsymbol{X} \\
\mathbf{p u}\end{array}$ & $\begin{array}{c}\boldsymbol{R} \boldsymbol{m} \\
\mathbf{p u}\end{array}$ & $\begin{array}{c}\boldsymbol{X} \boldsymbol{m} \\
\mathbf{p u}\end{array}$ & $\begin{array}{c}\boldsymbol{S n} \\
\mathbf{k V A}\end{array}$ & $\begin{array}{c}\boldsymbol{N p} / \mathbf{N} \boldsymbol{s} \\
\mathbf{k V} / \mathbf{k V}\end{array}$ \\
\hline $\mathrm{TD} / \mathrm{F}$ & 7 & 0.002 & 0.021 & 500 & 500 & 120 & $0.38 / 13.8$ \\
\hline
\end{tabular}

$R$ and $X$ : winding resistance and reactance; $R_{m}$ and $X_{m}$ : magnetization resistance and reactance; $S_{N}$ : rated power; $N_{p} / N_{s}$ : voltage transformation ratio

TABLE X:

Line filter capacitor data of the DSTATCOM

\begin{tabular}{cccc}
\hline ID & Bus & $\begin{array}{c}\boldsymbol{U n} \\
\mathbf{k V}\end{array}$ & $\begin{array}{l}\boldsymbol{C} \\
\boldsymbol{\mu} \mathbf{F}\end{array}$ \\
\hline $\mathrm{CD} / \mathrm{F}$ & 7 & 13.8 & 4 \\
\hline$U_{N}:$ rated voltage; $C$ : capacitance & &
\end{tabular}

\section{APPENDIX C. CONSTANT DATA OF THE CONTROL}

The most important data for the constants of the control algorithm of the DSTATCOM/FESS device are presented below.

$K_{u}=1 \quad K_{q}=1 \quad K_{p}=1 \quad R_{q}=0.01$

$K_{u}$ : gain of the $\mathrm{VCM}$

$K_{q}$ : gain of the PFCM

$K_{p}$ : gain of the APCM

$R_{q}$ : regulation characteristic of the voltage control system

Values of PI constants of the DSTATCOM control are shown in Table XI. All PI compensators are designed in the time domain using the following performance specifications for all signals: Overshoot $=5 \%$, Settling time $=2 \mathrm{~ms}$ and Steady-state error $=0.2 \%$. 
TABLE XI:

Values of PI constants of the DSTATCOM/FESS control

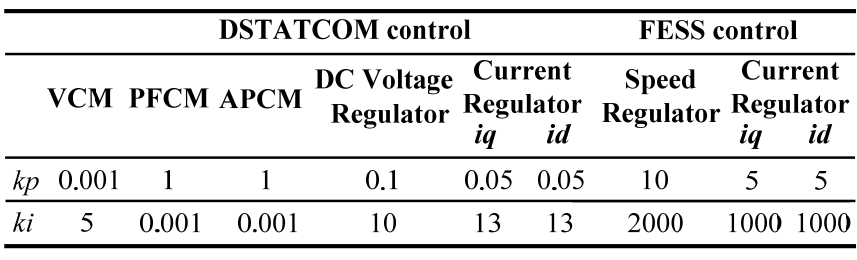

\section{BIOGRAPHIES}

Gastón Orlando Suvire was born in San Juan, Argentina, on November 13, 1977. He graduated as an electric engineer from the National University of San Juan (UNSJ), Argentina in 2002. He received his Ph.D. from the same University in 2009, carrying out part in the COPPE institute, in the Federal
University of Rio de Janeiro in Brazil. His research interests include simulation methods, power systems dynamics and control, power electronics modeling and design, and the application of wind energy and energy storage in power systems.

Pedro Enrique Mercado ( $\left.\mathrm{M}^{\prime} 02, \mathrm{SM}^{\prime} 02\right)$ was born in San Juan, Argentina, on August 26, 1953. He graduated as an electromechanical engineer from the UNSJ, and received his Ph.D. from the Aachen University of Technology, Germany. Dr. Mercado is currently a professor of electrical engineering at the UNSJ and a researcher with CONICET. He is a Senior Member of the IEEE Power Engineering Society. His research activities are focused on dynamic simulation, operation security, power electronics, economic operation and control of electric power systems. 